\title{
Apical third enlargement of the root canal and its relationship with the repair of periapical lesions
}

\author{
Ronaldo Araújo Souza' \\ João Costa Pinto Dantas' \\ Paula Maciel Brandão² \\ Suely Colombo ${ }^{1}$ \\ Maurício Lago ${ }^{1}$ \\ Marco Antônio Húngaro Duarte ${ }^{3}$
}

\section{ABSTRACT}

Objective: The purpose of this study was to evaluate if the apical third enlargement of root canal is the determinant factor for the repair of periapical lesions in endodontic treatment.

Methods: Eighty upper and lower incisors, canines and premolars with periapical lesions were randomly divided in 2 groups and were treated by undergraduate students. Canals were instrumented with up to 3 files in group I $(n=40)$ and up to 4 files in group II $(n=40) 1 \mathrm{~mm}$ short of the apex and were filled with a calcium hydroxide dressing. After removing calcium hydroxide 14 days later, both groups were filled using the lateral condensation technique. In the 2-year follow-up, a few patients did not return, and some cases did not present conditions for accurate comparisons. Therefore, only 43 patients (24 in group I and 19 in group II) presented conditions for radiographic comparisons. Data were statistically analyzed using Fisher's exact test.

Results: Comparison of the initial and follow-up radiographs showed that 22 out of 24 (91.67\%) patients in group I and 17 out of 19 patients (89.47\%) in group II showed repair. Statistical analysis revealed no significant differences between the groups $(P>05)$.

Conclusion: The results of this study show that the apical third enlargement did not alter the outcome of endodontic treatment of teeth with periapical lesion performed by undergraduate students. (Eur J Dent 2012;6:385-388)

Key words: Root canal instrumentation; periapical lesion; repair; endodontics

1 Department of Endodontics, School of Dentistry of Bahiana School of Medicine and Public Health, Bahia, BRAZIL

2 Private practice, Bahia, BRAZIL

3 Department of Endodontics, School of Dentistry of Bauru, University of São Paulo, SP, BRAZIL

- Corresponding author: Dr. Ronaldo Araújo Souza Av. Paulo VI, 2038/504, Ed. Villa Marta, 41.810-001, Itaigara, Salvador, Bahia, BRAZIL

Tel/Fax: +55 7133585396

Email: ronaldosouza.endodgmail.com

\section{INTRODUCTION}

Enlargement of root canals is long dated and supported by literature. ${ }^{1,2}$ In straight canals, it is a rather simple procedure; however, in curved canals, it represents a difficult task. The size at which the apical third of these root canals will be enlarged represents one of the most controversial topics in endodontics. ${ }^{3}$

In order to overcome such difficulties, many techniques have been proposed and some of them 
establish to start the instrumentation with a file that binds at working length and more 3 or 4 of increasing size besides it. ${ }^{4}$ On the other hand, more recently, a single instrument has been proposed to instrument the root canal. ${ }^{5}$

Yared and Bou Dagher ${ }^{6}$ reported that the canals instrumented to a $25 \mathrm{~K}$-file were as clean as those instrumented to a $40 \mathrm{~K}$-file with no significant difference regarding the bacterial elimination from the root canals. There was no significant difference in the elimination of bacteria between the palatal canals of the upper molars submitted to apical enlargement up to a $35 \mathrm{~K}$-file and those that were enlarged to smaller file sizes. ${ }^{7}$

Conversely, Rollison et $\mathrm{al}^{8}$ observed that the apical enlargement to a size \#50 K-file in mesiobuccal canals of mandibular molars provided greater reduction in the amount of bacteria than in teeth enlarged to a $35 \mathrm{~K}$-file. Hecker et $\mathrm{al}^{9}$ stated that the apical preparation size in 2-canal upper premolars and mandibular premolars should be at least 6 sizes larger than the first apically binding file, whereas in upper premolars with a central canal, the root canal should be enlarged to 8 sizes larger. Root canals should be shaped to larger sizes than normally recommended. ${ }^{10}$

The association of enlargement to a greater ability to remove infected contents of the root canal is widely accepted, ${ }^{11}$ but at the same time, it is rather controversial, and no study has ever shown a direct relation between apical enlargement and clinical success or failure. ${ }^{12}$

The purpose of this study was to investigate if the enlargement of root canals in cases of necrotic pulp and periapical lesion performed by undergraduate students is a true determinant factor for the repair.

\section{MATERIAL AND METHODS}

Eighty males and females patients aged 20-50 years, who were not under antibiotics and had no systemic diseases, such as uncontrolled hypertension and uncontrolled diabetes mellitus, were randomly included in this study after signing an informed consent in agreement to its terms. The study was approved by the Research Ethics Committee of the School of Dentistry of Bahiana School of Medicine and Public Health.

Single-rooted upper and lower incisors, canines and premolars with 1 canal were endodonti- cally treated by the undergraduate students at the School of Dentistry of Bahiana School of Medicine and Public Health. The presence of necrotic pulp and periapical lesion of no more than $5 \mathrm{~mm}$ of diameter was the inclusion criteria adopted for this study. Teeth with incompletely formed apices confirmed by radiographic evaluation or the presence of accidents or complications during treatment lcalcified canals, impossibility of achieving apical patencyl and periodontal probing outside normal limits were exclusion criteria also adopted.

A complete clinical record containing the patients' main concern, clinical and radiographic aspects of the teeth, results of pulp sensitivity and percussion tests as well as the endodontic procedures performed were maintained for each patient participating in the study.

Access and preparation of the pulp chamber were carried out with a \#3 carbide round bur (KG Sorensen, Cotia, Brazil) and Endo-Z bur (Maillefer, Ballaigues, Switzerland). Crown-down technique by using manual watch-winding motion with Flexofile (Maillefer, Ballaigues, Switzerland) was carried out and size 2 and 3 Gates-Glidden drills prepared the cervical and the middle thirds of the canals.

Canals were instrumented up to 3 files (the bound file and 2 files beyond it) in group I ( $n=40$ ) and up to 4 files (the bound file and 3 files beyond it) in group II ( $\mathrm{n}=40) 1 \mathrm{~mm}$ short of the apex.

Irrigation with 2-mL 2.5\% sodium hypochlorite (Q-Boa - Indústrias Anhembi S/A, Osasco, Brazil) was performed using a 5-mL Plastic Syringe 10pk and capillary tip (Ultradent Products Inc., South Jordan, UT, USA) at each instrument change, with the irrigation needle positioned at 5-mm short of the apex. Moreover, foramen cleaning was carried out in all of the teeth with a file that was bound to the walls of the foramens ${ }^{11}$ by using manual watch-winding motion. After instrumentation, root canals were irrigated with $3-\mathrm{mL}$ sterile saline and dried with paper points.

For the smear layer removal, the canals were irrigated with 1-mL 17\% EDTA (INODON - Porto Alegre, Brazil), which was agitated by a lentulo spiral (FKG Dentaire, La-Chaux-de-Fonds, Switzerland) and maintained in the root canal for $3 \mathrm{~min}$. Then, they were irrigated with $2-\mathrm{mL} 2.5 \%$ sodium hypochlorite, which was also agitated by a lentulo spiral and left in the canals for $5 \mathrm{~min}$. Root canals 
were then irrigated with $4 \mathrm{~mL}$ of sterile saline, dried with paper points, and filled with a calciumhydroxide saline paste carried by a lentulo spiral.

After 14 days, calcium hydroxide was removed, and both groups were filled with gutta-percha cones (Dentsply, Petrópolis, Brazil) and Endofill sealer (Dentsply, Petrópolis, Brazil) by lateral condensation technique.

Three radiographic aspects were considered to analyze treatment outcome: (1) complete healing (new bone formation and reestablishment of anatomic reference points: the lamina dura and the periodontal ligament width), (2) incomplete healing (decreasing of the lesion), and (3) failure (persistence of the lesion). Data were statistically analyzed by Fisher's exact test by using the GraphPad Prism (GraphPad, La Jolla, CA).

\section{RESULTS}

In the 2-year follow-up, a few patients did not return and some cases did not present conditions for comparisons, such as errors in the clinical records or poor quality of radiographs, and therefore they were excluded from the study. Overall, 37 patients were excluded. Of the 43 remaining patients, 24 had root canals instrumented up to 3 files (group I), whereas 19 had root canals instrumented with 4 files (group II).

Comparison of the initial and the follow-up radiographs showed that $22(91.67 \%)$ patients in group I and 17 (89.47\%) in group II presented complete repair. Statistical analysis carried out by Fisher's exact test revealed no significant differences between the groups ( $P>$.05).

These data are presented in Table 1.

\section{DISCUSSION}

Preparation of root canal should not be considered only for shaping, but also for cleaning. ${ }^{14-16}$ It is reasonable to suppose that the greater the enlargement, the less likely that the microorganisms remain inside the root canal. ${ }^{11}$

However, considering the real anatomic diameter of the root canal at the apex, ${ }^{17}$ it is possible that the actual protocols of instrumentation do not completely fulfill the ideal standards for apical enlargement. Such limitation may be still greater if we consider that many root canals are not circular in the apical third, presenting 2 diameters. ${ }^{18}$

A few patients did not return for follow-up in our study and some cases did not present the best conditions for radiographic comparisons, but even considering that there was not a high sample size, the results seem to demonstrate that there is no direct correlation between the enlargement and the repair of periapical lesions.

In group I, 22 of the 24 (91.67\%) periapical lesions showed complete healing and 2, (8.33\%) failure. They are very similar to the results of group II, in which in 19 cases instrumented with 4 files, 17 (89.47\%) were considered as completely healed, whereas 2 (10.53\%) were not.

One possible explanation for these results is the adjuvant action of the irrigating solutions ${ }^{19}$ and their solvent and antimicrobial properties and also the action of intracanal medication. ${ }^{20,21}$

Understanding that the levels of enlargement used in this study do not represent a suggestion for root canal instrumentation is of utmost importance. Considering that the treatments were performed by dental students, which by itself reflects a situation of greater technical limitations, ${ }^{22-25}$ by using manual stainless steel instruments, the anatomic conditions were a factor dictating the extent of instrumentation.

It is possible that a better approach would be the instrumentation of curved canals, such as molars, with NiTi files, performed by experienced endodontists, but the purpose was not to evaluate the characteristics of the instruments or the root canal anatomy. The aim was to investigate the effect that apical third enlargement of the canal would have on the repair of periapical lesions in the endodontic treatment performed by undergraduate students.

It must be understood that root canals should be adequately instrumented. The mechanical action of instrumentation represents a major step in root canal preparation, but it does not seem reasonable to predetermine rules for instrumenta-

Table 1. Number of root canals treated and frequency of treatment success.

\begin{tabular}{llll}
\hline Groups & Number of Root Canals & Success & Failure \\
\hline I & 24 & $22(91,67 \%)$ & $2(8,33 \%)$ \\
II & 19 & $17(89,47 \%)$ & $2(10,53 \%)$ \\
\hline
\end{tabular}


tion, as it has been done so far. It is not wise to predetermine levels of enlargement for different root canals with its diverse anatomic characteristics such as curvature, diameter and length.

\section{CONCLUSION}

The results of this study show that the apical third enlargement did not alter the outcome of endodontic treatment of teeth with periapical lesion performed by undergraduate students. They suggest that the repair of the periapical lesion may not have solely a direct relationship with the apical enlargement of root canals. Further clinical studies focusing on this topic should be carried out in order to better define this question.

\section{REFERENCES}

1. Tasdemir T, Er K, Celik D, Yildirim T. Effect of passive ultrasonic irrigation on apical extrusion of irrigating solution. Eur J Dent 2008;2:198-203.

2. Kustarci A, Akdemir N, Siso SH, Altunbas D. Apical extrusion of intracanal debris using two engine driven and stepback instrumentation techniques: an in-vitro study. Eur $J$ Dent 2008;2:233-239.

3. Hülsmann M, Peters OA, Dummer PMH. Mechanical preparation of root canals: shaping goals, techniques and means. Endod Topics 2005;10:30-76.

4. Weine F S. Endodontic Therapy, 5th ed, St. Louis: Mosby, 1996.

5. Peters OA, Paqué F. Root canal preparation of maxillary molars with the self-adjusting file: a micro-computed tomography study. J Endod 2011;37:53-57.

6. Yared GM, Bou Dagher FE. Influence of apical enlargement on bacterial infection during treatment of apical periodontitis. J Endod 1994;20:535-537.

7. Coldero LG, McHugh S, MacKenzie D, Saunders WP. Reduction in intracanal bacteria during root canal preparation with and without apical enlargement. Int Endod $J$ 2002;35:437-446.

8. Rollison S, Barnett F, Stevens RH. Efficacy of bacterial removal from instrumented root canals in vitro related to instrumentation technique and size. Oral Surg Oral Med Oral Pathol Oral Radiol Endod 2002;94:366-371.

9. Hecker H, Bartha T, Löst C, Weiger R. Determining the apical preparation size in premolars: part III Oral Surg Oral Med Oral Pathol Oral Radiol Endod 2010;110:118-124.

10. Weiger R, Bartha T, Kalwitzki M, Löst C. A clinical method to determine the optimal apical preparation size. Part I. Oral Surg Oral Med Oral Pathol Oral Radiol Endod 2006;102:686691.
11. Mickel AK, Chogle S, Liddle J, Huffaker K, Jones JJ. The role of apical size determination and enlargement in the reduction of intracanal bacteria. $J$ Endod 2007;33:21-23.

12. Negishi J, Kawanami M, Ogami E. Risk analysis of failure of root canal treatment for teeth with inaccessible apical constriction. J Dent 2005;33:399-404.

13. Souza RA. The importance of apical patency and cleaning of the apical foramen on root canal preparation. Braz Dent $J$ 2006;17:6-9.

14. Wu M-K, Dummer PMH, Wesselink PR. Consequences of and strategies to deal with residual post-treatment root canal infection. Int Endod J 2006;39:343-356.

15. Chuste-Guillot M-P, Badet C, Peli J-F, Perez F. Effect of three nickel-titanium rotary file techniques on infected root dentin reduction. Oral Surg Oral Med Oral Pathol Oral Radiol Endod 2006;102:254-258.

16. Fornari VJ, Silva-Sousa YTC, Vanni JR, Pécora JD, Versiani MA, Sousa-Neto MD. Histological evaluation of the effectiveness of increased apical enlargement for cleaning the apical third of curved canals. Int Endod J 2010;43:988-994.

17. Pécora JD, Capelli A, Guerisoli DMZ, Spanó JCE, Estrela C. Influence of cervical preflaring on apical file size determination. Int Endod J 2005;38:430-435.

18. Green EN. Microscopic investigation of root canal diameter. JADA 1958;57:636-644.

19. Kanisavaran ZM. Chlorhexidine gluconate in endodontics: an update review. Int Dent $J$ 2008;58:247-257.

20. Mohammadi Z, Farhad A, Tabrizizadeh M. One-visit versus multiple-visit endodontic therapy - a review. Int Dent $J$ 2006;56:289-293.

21. Oliveira DP, Barbizam JVB, Trope M, Teixeira FB. In vitro antibacterial efficacy of endodontic irrigants against Enterococcus faecalis. Oral Surg Oral Med Oral Pathol Oral Radiol Endod 2007;103:702-706.

22. Hayes SJ, Gibson M, Hammond M, Bryant ST, Dummer $\mathrm{PMH}$. An audit of root canal treatment performed by undergraduate students. Int Endod J 2001;34:501-505.

23. Kfir A, Rosenberg E, Zuckerman O, Tamse A, Fuss Z. Comparison of procedural errors resulting during root canal preparations completed by junior dental students in patients using an '8-step method' versus 'serial step-back technique'. Int Endod J 2003;36:49-53.

24. Khabbaz MG, Protogerou E, Douka E. Radiographic quality of root fillings performed by undergraduate students. Int Endod J 2010;43:499-508.

25. Unal GC, Kececi AD, Kaya BU, Tac AG. Quality of root canal fillings performed by undergraduate dental students. Eur $J$ Dent 2011;5:324-330. 